\title{
Spectrum of histomorphological diagnosis in cystoscopic bladder biopsies
}

\author{
Thapa $\mathrm{R}^{1}$, Lakhey $\mathrm{M}^{1}$, Bhatta $\mathrm{AD}^{2}$ \\ ${ }^{I}$ Department of Pathology, Medicare National Hospital \& Research Centre, Kathmandu, Nepal \\ ${ }^{2}$ Department of Urology, Medicare National Hospital \& Research Centre, Kathmandu, Nepal
}

\author{
Keywords: \\ Low grade; \\ High grade; \\ Papilloma; \\ Urothelial carcinoma
}

\begin{abstract}
Background: Urinary bladder lesions are the main source of significant clinical symptoms which are more disabling than lethal. Bladder tumors constitute one of the most common urological pathology. Urothelial carcinoma accounts for $90 \%$ of all primary tumors of the bladder. This study aimed to determine the frequency of different types of lesions of the urinary bladder and to determine the grade and stage of urothelial tumors.

Materials and methods: This is a 2 years prospective study of cystoscopic biopsies carried out in the Department of Pathology, Medicare National Hospital and Research Centre, Kathmandu, Nepal.

Result: Out of 87 cases, 58 (66.67\%) cases were neoplastic lesions and 29(33.33\%) cases were nonneoplastic lesions. Majority of neoplastic lesions $96.55 \%$ were urothelial (transitional cell) tumors comprising predominantly of low grade papillary urothelial carcinoma 50.91\%. Muscle invasion was seen only in high grade papillary urothelial carcinomas.
\end{abstract}

Conclusion: Among bladder tumors low grade papillary urothelial carcinoma is the most common.

\section{INTRODUCTION}

Urinary bladder lesions, both non-neoplastic and neoplastic, are common in the Nepalese community. They are often disabling but rarely lethal. Tumors of the bladder are an important source of both morbidity and mortality. ${ }^{1}$ Worldwide, urinary bladder cancer is the seventh most common cancer, with an estimated global incidence of

\section{Correspondence:}

Dr Rupendra Thapa, MBBS, MD

Department of Pathology

Medicare National Hospital \& Research Centre, Kathmandu, Nepal.

Email; rup432@gmail.com
330380 new cases in 2012. ${ }^{2}$ Urothelial carcinoma is the commonest type accounting for $90 \%$ of all primary tumors of the bladder. ${ }^{3}$ The incidence of carcinoma of the bladder is higher in men than in women, in developed than in developing nations, and in urban than in rural dwellers. About $80 \%$ of patients are between 50 and 80 years of age. ${ }^{1}$ At least $75-80 \%$ of newly diagnosed bladder cancers are superficial, non- invasive papillary urothelial carcinoma, and at least $50-75 \%$ of these patients will recur over time. This high recurrence rate impacts heavily on prevalence rates making bladder cancer the second most common cancer behind prostate cancer in males. ${ }^{4}$ Neoplastic lesions 
Table 1: Distribution of cases according to histomorphological diagnosis

\begin{tabular}{clcc}
\hline $\mathbf{S .}$ No & Histomorphological Diagnosis & No. of cases & Percentage \\
\hline $\mathbf{I}$ & NON - NEOPLASTIC LESIONS & 29 & $33.33 \%$ \\
\hline $\mathbf{1}$ & Chronic non-specific cystitis & 11 & $12.63 \%$ \\
\hline $\mathbf{2}$ & Eosinophilic cystitis & 4 & $4.60 \%$ \\
\hline $\mathbf{3}$ & Acute on chronic cystitis & $2.30 \%$ \\
\hline $\mathbf{4}$ & Urethral carbuncle & 2 & $2.30 \%$ \\
\hline $\mathbf{5}$ & Follicular cystitis & 2 & $1.15 \%$ \\
\hline $\mathbf{6}$ & Cystitis cystica with Von Brunn's nest & 1 & $4.60 \%$ \\
\hline $\mathbf{7}$ & Cystitis glandularis & $2.30 \%$ \\
\hline $\mathbf{8}$ & Squamous metaplasia & $1.15 \%$ \\
\hline $\mathbf{9}$ & Tubercular cystitis & 2 & $1.15 \%$ \\
\hline $\mathbf{1 0}$ & Bladder diverticulum & 1 & $1.15 \%$ \\
\hline & & 1 & \\
\hline $\mathbf{I I}$ & NEOPLASTIC LESIONS & 1 & $66.67 \%$ \\
\hline $\mathbf{A}$ & Benign & & $5.75 \%$ \\
\hline $\mathbf{B}$ & Urothelial papilloma & 58 & $5.75 \%$ \\
\hline $\mathbf{1}$ & Ualignant & 5 & $60.92 \%$ \\
\hline $\mathbf{2}$ & Squamolial carcinoma & 5 & $58.62 \%$ \\
\hline & Total & 53 & $2.30 \%$ \\
\hline
\end{tabular}

Table 2: Histological grading of urothelial neoplasm as per ISUP/WHO 2004

\begin{tabular}{clcc}
\hline S.No & Grade & No. of cases & Percentage \\
\hline $\mathbf{1}$ & Papilloma & 5 & $8.93 \%$ \\
\hline $\mathbf{2}$ & PUNLMP & 6 & $10.71 \%$ \\
\hline $\mathbf{3}$ & Low grade papillary urothelial carcinoma & 28 & $50 \%$ \\
\hline $\mathbf{4}$ & High grade papillary urothelial carcinoma & 17 & $30.36 \%$ \\
\hline & Total & $\mathbf{5 6}$ & $\mathbf{1 0 0 \%}$ \\
\hline
\end{tabular}

of bladder pose biologic, clinical, diagnostic and therapeutic challenges to both urologist and pathologist, as these tumors represent a heterogeneous group of tumors with different subtypes and behavioral patterns. . $^{1,5}$

Cystoscopic bladder biopsy is a gold standard for accurate diagnosis and prognostic assessment of the patient. Hence, this study was undertaken to determine the frequency of different types of lesions of the urinary bladder and to determine the grade and stage of urothelial tumors so as to prevent mortality and morbidity associated with it.

\section{MATERIAL AND METHODS}

This is a prospective study carried out in the Department of Pathology, Medicare National Hospital and Research Centre, Kathmandu, Nepal, over a period of two years from September 2014 to August 2016. All the patients who visited Urology Department and subjected to cystoscopic biopsy were included in this study. The cystoscopic bladder biopsies taken were fixed in 10\% formalin and then processed. Four microns thick sections were taken and stained with Haematoxylin and Eosin stain (H\&E). Special stains were used whenever required.

The World Health Organization (WHO)/International Society of Urological Pathology (ISUP) classification (2004) was used to grade the tumors into: urothelial papilloma, papillary urothelial neoplasm of low malignant potential (PUNLMP), low and high grade urothelial (transitional cell) carcinomas (TCC). Pathological staging of the urothelial cancers was done according to the TNM system and data recorded as pTa: tumor limited to mucosa, pT1: invasion of lamina propria and pT2 as invasion of muscle. 6

Inclusion criteria: All the transurethral resection of bladder tissue (TURBT) biopsies received in the Department of Pathology.

Exclusion criteria: Autolysed and inadequate biopsies were excluded.

The main purpose of this study was to determine the 
Table 3: Histological staging of urothelial neoplasm as per TNM staging

\begin{tabular}{|c|c|c|c|c|c|}
\hline S .No & Staging & No .of cases & & Total & Percentage \\
\hline & & LGPUC & HGPUC & & \\
\hline 1 & $\mathrm{pTa}$ & 18 & 1 & 19 & $42.22 \%$ \\
\hline 2 & pT1 & 10 & 5 & 15 & $33.33 \%$ \\
\hline \multirow[t]{2}{*}{3} & pT2 & 0 & 11 & 11 & $24.45 \%$ \\
\hline & Total & 28 & 17 & 45 & $100 \%$ \\
\hline
\end{tabular}

frequency of different types of lesions of the urinary bladder and the grade and stage of urothelial tumors.

\section{RESULTS}

A total of 87 cystoscopic biopsies were analyzed during the study period. Among these study population, 64 cases (73.56\%) were males and 23 cases $(26.44 \%)$ females with male to female ratio of 2.7:1. Similarly male preponderance was observed among neoplastic lesion with male to female ratio of $3.8: 1$ with 46 cases $(79.31 \%$ ) being male and 12 cases $(20.69 \%)$ being female. Age of the study population ranged from 21 to 80 years. The peak incidence was seen between $61-70$ years followed by 71-80 years group. More than $50 \%$, i.e. $65.1 \%(n=57)$ of bladder lesions of both sexes were observed above 50 years of age.

Spectrum of different pathological lesions was observed (Table 1). Out of 87 cases, $58(66.67 \%)$ were neoplastic lesions and 29(33.33\%) were non- neoplastic lesions. Out of $58(66.67 \%)$ neoplastic lesions, 56(96.55\%) were urothelial (transitional cell) tumors. As per histological grading WHO/ISUP (2004) used in the study showed high prevalence of low grade urothelial carcinoma, followed by high grade urothelial carcinoma, papillary urothelial neoplasm of low malignant potential( PUNLMP) and urothelial papilloma accounting for $50 \%, 30.36 \%, 10.71 \%$ and $8.93 \%$ respectively. (Table 2 ) As per TNM staging used in our study we observed majority of the bladder tumors were invasive accounting for $45(77.59 \%)$ cases out of which $19(42.22 \%)$ cases were in pTa stage , $15(33.33 \%)$ cases were in pT1 and 11(24.45\%) cases were in pT2 stage. Muscle invasion was seen in $11(24.45 \%)$ cases of high grade papillary urothelial carcinoma whereas none of the cases of low grade papillary urothelial carcinoma showed muscle invasion. (Table 3)

\section{DISCUSSION}

The present study revealed variable histomorphologic diagnosis of bladder lesions as shown in table 1. Among the non-neoplastic lesions, chronic nonspecific cystitis was the most common accounting for $11(12.63 \%)$ cases. This finding is comparable with study done by Dravid et al where nonspecific cystitis was seen in 18 (12.94\%)cases and with Vaidya et al where cystitis cases were $16(14.95 \%)^{7,8}$

The demographic characteristics of the patients in current study were relatively similar to a number of studies which describe a peak incidence of bladder lesions in the age 61 -70 years and predominance in male with male to female ratio of $2.78: 1$. The increase prevalence of bladder cancers in males than in females is probably related to difference in smoking habits and occupational exposure. ${ }^{1,9}$

Bladder tumors were the most common type of lesion in the present study and were seen in $58(66.67 \%)$ cases of which 55 (94.83\%) cases were urothelial (transitional cell) tumors. Majority were malignant neoplasm comprising of 51 $(58.62 \%)$ cases of urothelial carcinoma and $2(2.30 \%)$ cases of squamous cell carcinoma which were in concordance with following studies done by Mahesh K et al, Mohammad

Table 4: Comparison of frequency of various malignant neoplasm of bladder in different studies

\begin{tabular}{lcccc}
\hline Neoplastic lesions & Mahesh K et al $^{\mathbf{1 0}}$ & Mohammad M et al $^{1 \mathbf{1}}$ & ${\text { Dravid et } \mathbf{a l}^{\mathbf{7}}}$ & Present study \\
\hline Urothelial carcinoma & $28(46.6 \%)$ & $467(93.3 \%)$ & $77(53.39 \%)$ & $51(58.62 \%)$ \\
\hline Squamous cell carcinoma & $2(3.33 \%)$ & $13(2.6 \%)$ & $7(5.03 \%)$ & $2(2.30 \%)$ \\
\hline
\end{tabular}

Table 5: Comparison of frequency of histological grades of bladder neoplasms in different studies

\begin{tabular}{|c|c|c|c|c|c|}
\hline Grading & Laishram et al $^{12}$ & 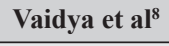 & 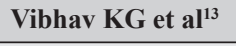 & Dravid et al $^{7}$ & Present study \\
\hline PUNLMP & $7.69 \%$ & $10.28 \%$ & $4.1 \%$ & $5.43 \%$ & $10.71 \%$ \\
\hline LGPUC & $53.85 \%$ & $29.91 \%$ & $32.29 \%$ & $22.82 \%$ & $50 \%$ \\
\hline HGPUC & $34.61 \%$ & $32.7 \%$ & $60.41 \%$ & $55.43 \%$ & $30.36 \%$ \\
\hline
\end{tabular}

Table 6 Comparison of frequency of histological stages of bladder neoplasms in different studies

\begin{tabular}{ccccc}
\hline TNM Stage & Laishram et al & Dravid et al $^{\mathbf{7}}$ & Vaidya et al $^{8}$ & Present study $^{\mathbf{2}}$ \\
\hline pTa & $14(53.85 \%)$ & $20(21.73 \%)$ & $39(48.14 \%)$ & $19(42.22 \%)$ \\
\hline pT1 & $4(15.38 \%)$ & $49(53.26 \%)$ & $18(22.22 \%)$ & $15(33.33 \%)$ \\
\hline pT2 & $8(30.77 \%)$ & $18(19.56 \%)$ & $24(29.63 \%)$ & $11(24.45 \%)$ \\
\hline
\end{tabular}


M et al and Dravid et al ( table 4).,10,11

The histological grading of the urothelial neoplasm in present study showed increased prevalence of low grade papillary urothelial carcinoma (LGPUC) correlated with similar studies as shown in table 5.7,8,12,13 Histological grading and staging are the two important factors for tumor recurrence, progression and for determination of treatment options for patients with bladder carcinoma. ${ }^{14}$ In present study we observedmajority of the malignant bladder tumors were invasive, accounting for $45(77.59 \%)$ cases out of which $19(42.22 \%)$ cases were in pTa stage, $15(33.33 \%)$ cases were in pT1 and 11(24.45\%) cases were in pT2 stage. This findings were comparable with similar studies shown in table 6.,8,12 Muscle invasion was seen in $11(24.45 \%)$ cases of high grade papillary urothelial carcinoma whereas none of the cases of low grade papillary urothelial carcinoma showed muscle invasion.

\section{CONCLUSION}

This study revealed a wide spectrum of non- neoplastic and neoplastic urinary bladder lesions. Majority of the cases were malignant bladder neoplasms of urothelial origin, large number of which was low grade papillary urothelial carcinoma.The importance of including muscle in cystoscopic biopsies needs to be emphasized as muscle invasion is an important predictor of prognosis.

\section{REFERENCES}

1. Epstein JI. The lower urinary tract and male genital system. In : Kumar V, Abbas AK, Fausto N, eds. Robbins and Cortan Pathologic Basis of Disease. 7th ed. Philadelphia: Saunders; 2004.1026-36 pp .

2. Grignon DJ, Al- Ahmadie H, Algaba F et al. Tumors of the urinary tract: Infiltrating urothelial carcinoma. In Moch H, Humphrey PA, Ulbright TM, Reuter VE.eds, WHO Classification of Tumors of the Urinary System and Male Genital Organs, Lyon, France: IARCC Press, 2016:81-133 .

3. Kumar MU, Yelikar BR. Spectrum of Lesions in Cystoscopic Bladder Biopsies - A Histopathological study. Al ameen J Med Sci 2012:5:132-6.

4. Boustead GB, Fowler S, Swamy R et al. Stage, grade and pathological characteristics of bladder cancer in the UK: British Association of Urological Surgeons (BAUS) Urological Tumour Registry. BJU Int 2014;113:924-30. Crossref

5. Hussain N, Shumo A, Mekki S et al. A clinicopathological study of urinary bladder neoplasms in patients at three centers in Khartoum, sudan. Sudan Journal of Medical Science 2009;4:249-55 . Crossref

6. Eble JN, Sauter G, Epstein JI et al. Tumors of urinary system. In: WHO Classification of Tumors - Pathology and Genetics of Tumors of the Urinary System and Male Genital Organs. Lyon: IARC Press;2004:89-158 .
7. Dravid NV, Rajeshwori K, Karibasappa GN et al. Histomorphological Profile of Lesions in Cystoscopic Bladder Biopsies - A prospective Study in North Maharashtra. Int Clin Pathol J 2016;3:00064. Crossref

8. Vaidya S, Lakhey M, KC Sabira et al. Urothelial Tumors of the Urinary Bladder: A Histopathological Study of Cystoscopic Biopsies.J Nepal Med Assoc 2013;52:475-8 . Crossref

9. Gupta P, Jain M, Kapoor R et al. Impact of age and gender on the clinicopathological characteristics of bladder cancer. Indian J Urol 2009;25:207-10. Crossref

10. Mahesh K and BR Yelikar. Spectrum of lesions in cystoscopic bladder biopsies - A histopathological study. Al Ameen J Med Sci 2012;5:132-6.

11. Mohammed M, Javed IK, Altaf $\mathrm{H}$ et al. Urinary bladder tumors in southern Pakistan: A histopathological perspective. Middle East J Cancer 2014; 5:167-73.

12. Laishram RS, Kipgen $\mathrm{P}$, Laishram $\mathrm{S}$ et al. Urothelial tumors of the urinary bladder in Manipur: A histopathological perspective. Asia Pacific J Cancer Prev 2012;13:2477-9. Crossref

13. Vaibhav KG, Surendra PV, Dharm CK. Spectrum of lesions in urinary bladder biopsies: Histopathological study. Int J Dent Med Res 2015;1:42-6.

14. Matalka I, Bani - Hani K, Shotar A et al. Transitional cell carcinoma of the urinary bladder. A clinicopathological study.Singapore Med J 2008;49:790-4. Crossref 